\title{
Nutritional improvement of plant foods by non-thermal processing*
}

\author{
D. Knorr†, B. I. O. Ade-Omowayeł and V. Heinz \\ Department of Food Biotechnology and Food Process Engineering, Berlin University of Technology, Königin-Luise-Strasse \\ 22, D-14195 Berlin, Germany
}

\begin{abstract}
As a result of the increasing consumer demand for minimally-processed fresh-like food products with high sensory and nutritional qualities, there is a growing interest in non-thermal processes for food processing and preservation. Key advanced technologies such as high-pressure processing, pulsed electric fields, dense gases and ultrasound are being applied to develop gentle but targeted processes to further improve the quality and safety of processed foods. These technologies also offer the potential for improving existing processes as well as for developing new process options. Furthermore, by adding new process dimensions (such as hydrostatic pressure, electric fields, ultrasonics, supercritical $\mathrm{CO}_{2}$ ) to the conventional process variables of temperature and time, they facilitate enlargement of the availability of unit operations. These operations might be applied effectively in unique combination processes, or as subsequent processing tools in more-targeted and subsequently less-intensive processes for food preservation and modification than the currently-applied processes.
\end{abstract}

\section{Non-thermal food processing: Food preservation: Nutritional quality: High-pressure processing: Pulsed electric fields: Ultrasound}

Thermal processes such as blanching, pasteurisation or heat sterilisation have long been employed in practice as economic, efficient, reliable and safe food preservation methods. However, in most cases thermal energy induces various chemical reactions, leading to quality deterioration in certain foods by producing undesirable changes in sensory and nutritional qualities. Thus, preservation technologies that prolong shelf-life without these detrimental effects are to be favoured (Ohlsson, 1994). Increasing consumer demand for new products with inherent sensory and nutritional qualities has led to the development of gently (minimally)-processed foods. Consumer interest in gentlyprocessed foods springs from concerns associated with the fear of chemicals in the food supply, conflicting reports regarding the pros and cons of existing and new foodprocessing technologies, as well as increased awareness of nutritional issues (Thakur \& Nelson, 1998). This consumer attitude has spurred a search for new alternatives to processed foods. Non-thermal methods provide such an option because they offer fresh-like 'minimally'-processed foods with little loss of colour, flavour and nutrients. There are several new non-thermal technologies of potential interest to the industry, including high-pressure processing (HPP), pulsed electric fields (PEF), highintensity pulsed light, irradiation, ultrasound and modifiedatmosphere packaging (Hoover, 1997). Among the novel non-thermal technologies, the application of HPP, PEF and ultrasound to food processing and preservation has become of considerable interest in food research and development. These technologies are of specific interest to the food industry, because they not only provide attractive alternatives to conventional methods of thermal processing, which often produce undesirable changes in foods, affecting the balance between high quality and safety, but also offer opportunities for creating new ingredients and products because of the specific actions on biological materials and food constituents (Knorr, 1999). The potential to commercialise the non-thermal HPP and PEF technologies as new methods to preserve food products has caught the attention of a food industry wanting to satisfy the consumer's demands for fresh products. With diet and health firmly established as a long-term consumer lifestyle, it is important to understand the impact of the new technologies on the nutritional value of foods. The

\footnotetext{
Abbreviations: HPP, high-pressure processing; PEF, pulsed electric fields.

*The other papers presented at this meeting were published in Proceedings of the Nutrition Society (2001), 60, 463-496.

†Corresponding author: Professor D. Knorr, fax +4930 8327663, email foodtech@ mailszrz.zrz.tu-berlin.de

†On a German Academic Exchange Service (DAAD) fellowship from: Department of Food Science and Engineering, Ladoke Akintola University of Technology, Ogbomoso, Nigeria.
} 
present paper will discuss some of the nutritional improvements encountered during HPP, PEF and ultrasound processing.

\section{Basic principles and advantages of non-thermal technologies}

HPP offers the food industry a unique opportunity to develop new foods of improved nutritional and sensory quality, novel texture, more convenience, higher safety and increased shelf-life than conventionally-processed products. Just as for thermal processing, food can be high-pressure processed in two fundamentally different ways: in-container (HPP is executed after filling and sealing of the food into its final or intermediate package); in bulk followed by aseptic or ultra-clean filling and sealing (Mertens, 1995). In principle, high pressure inactivates micro-organisms, denatures proteins and gelatinises starches; effects similar to those of high temperature (Hayashi, 1996). The effect of pressure on biological or chemical systems is governed by the principle of Le Chetelier, which states that any reaction under equilibrium conditions accompanying a volume decrease is promoted by an increase in pressure (Thakur \& Nelson, 1998). The effect of pressure on the reaction rate can be described by the transition state theory, where the rate constant of a reaction in a liquid phase is proportional to the quasi equilibrium constant for the formation of active reactants. Based on this assumption, at isothermal conditions, the pressure dependence of the reaction velocity constant is due to the activation volume of the reaction (Knorr, 2002). HPP is an emerging technology with several advantages. The instant transmittance of high pressure throughout food systems and the consequent independence of size and geometry of the samples treated represents a major advantage over conventional thermal processing (Knorr, 1996). High pressure can be applied at room temperature, thus reducing the amount of thermal energy needed for food products during conventional processing. Also, high pressure does not affect covalent bonds, and development of flavours alien to the products is therefore prevented, hence maintaining the natural qualities of the products (Stute et al. 1996).

The use of PEF is one of the most promising emerging non-thermal processes, which has caught the attention of several research groups from around the world. PEF processing of foods involves the application of short pulses (duration of the order of $\mu s-m s$ ) of high electric field intensity. The technique is similar to that of electroporation (Neumann et al. 1989), which has been used successfully in biomedicine, cell biology and biotechnology (Chang et al. 1992). PEF treatment has also been applied to liquid foods for inactivation of micro-organisms and denaturation of enzymes (Barbosa-Canovas et al. 1999). A cell membrane exposed to a high-intensity electric field can be temporarily destabilised or irreversibly ruptured. The concept of membrane electroporation was based on its dielectric breakdown (Chang et al. 1992). The electrical damage may involve various mechanisms: critical transmembrane potential, visco-elastic properties, structural defects in the cell membrane, compression of the membrane and colloidal osmotic swelling (Bouzrara \& Vorobiev, 2000). It has been established from various studies that the PEF process has potential as an emerging unit operation in food processing, preservation and modification (Knorr \& Angersbach, 1998). The following advantages have been documented. The process is designated as a gentle and waste-free technology. Use of the PEF process has potential for continuous application, instant distribution throughout an electrically-conductive food, short treatment time, low energy requirements and allows food to retain its colour, flavour and nutritive value (Knorr \& Angersbach, 1998; Barsotti \& Cheftel, 1999). This technology offers great potential to the food industry because it can be applied to a wide range of products, as well as being an effective pre-processing technology (i.e. to improve heat and mass transfers).

Ultrasound is one of the alternative methods that has been tried as a replacement for heat in the preservation of foods. Ultrasound comprises vibrations similar to sound waves, but of a frequency too high $(18 \mathrm{kHz}-500 \mathrm{MHz})$ to be heard by the human ear (McClements, 1995). In biological media these vibrations produce cycles of compression and expansion, and subsequently the phenomenon of cavitation. The implosion of gas bubbles generates spots with very high pressures and temperatures that can disrupt cellular structures (Sala et al. 1995; I Álvarez, unpublished results). This intense energy input accelerates both physical and chemical reactions, enhancing surface chemistry, and causing violent particle motion, which generates highvelocity interparticle collisions. Ultrasonic techniques are finding increasing use in the food industry for both the analysis and modification of foods. Low-intensity ultrasound provides information about physico-chemical properties, while high-intensity ultrasound is used to alter, either physically or chemically, the properties of foods, e.g. to generate emulsions, disrupt cells, promote chemical reactions, inhibit enzymes, tenderise meat and modify crystallisation processes (McClements, 1995). The use of ultrasonics alone for microbial inactivation of foods appears ineffective, hence different authors have attempted to use it in combination with other anti-microbial methods to increase its effectiveness in microbial and enzyme inactivation (Hoover, 1997). Such combinations include thermosonication (heat + ultrasound), manosonication (pressure + ultrasound) and manothermosonication (pressure + heat + ultrasound). These combinations were found to be effective against micro-organisms and enzymes. The combined use of heat and ultrasound, or heat and ultrasound under pressure, markedly increases the lethality of heat treatments and consequent reductions in time and/or temperature of heat processes (Sala et al. 1995; I Álvares, unpublished results; Zenker et al. 2001). Combined heat and ultrasound treatments have been reported to lower maximum processing temperatures by 25-50\%. After treatment, changes in colour and vitamin C were minimal (Zenker et al. 2001).

\section{Product safety}

Product safety is the precondition for a food to be on the market, and the main factors involved include chemical 
Table 1. Effect of the application of high pressure on the reduction in total microbial counts (colony-forming units (CFU)/ml) in potato cubes in comparison with water blanching (Stute et al. 1996)

\begin{tabular}{cccc}
\hline \multicolumn{2}{c}{ High pressure $(400 \mathrm{MPa}$ for $15 \mathrm{~min})$} & \multicolumn{2}{c}{ Water blanching at $100^{\circ} \mathrm{C}$} \\
\cline { 1 - 2 } Temperature $\left({ }^{\circ} \mathrm{C}\right)$ & Total microbial counts & Time (s) & Total microbial counts (CFU/ml) \\
\hline 5 & $<10^{2}$ & 60 & $10^{3}$ \\
20 & $<10^{2}$ & 90 & $<10^{3}$ \\
35 & $<10^{2}$ & 120 & $<10^{3}$ \\
50 & $<10^{2}$ & 150 & $<10^{3}$ \\
\hline
\end{tabular}

safety and microbiological safety. The general advantage of these advanced technologies is the elimination of chemical additives.

\section{High pressure}

According to Hoover et al. (1989) HPP induces a number of changes in the morphology, biochemical reactions, genetic mechanisms, and cell membrane and wall of microorganisms. In general, HPP can inactivate vegetative micro-organisms, whereas bacterial spores appear to be resistant. However, several studies have indicated the possibility of reducing bacterial spores through combinations of mild heat and HPP (Knorr, 1995; Meyer et al. 2000). According to Stute et al. (1996) HPP reduces total microbial counts in potato cubes, similar to mild blanching (Table 1). Jam preparations were preserved by HPP (Horie et al. 1991). Pressure inactivation of yeasts and moulds has been reported in citrus juices (Ogawa et al. 1992). Juices pressurised at $400 \mathrm{MPa}$ for $10 \mathrm{~min}$ and at $40^{\circ} \mathrm{C}$ did not spoil during 2-3 months of storage. A population of $10^{6}$ colony-forming units Listeria monocytogenes/ml ultra-high temperature milk was inactivated by exposure to $340 \mathrm{MPa}$ at $23^{\circ} \mathrm{C}$ and the same initial population of Vibrio parahaemolyticus in clam juice was killed within $10 \mathrm{~min}$ of exposure to $170 \mathrm{MPa}$ at $23^{\circ} \mathrm{C}$ (Styles et al. 1991). Pressure treatment of non-pasteurised citrus juice resulted in a flavour close to freshly-squeezed juice, with no loss of vitamin $\mathrm{C}$ and a shelf-life of up to 17 months. It was reported that bacterial spores in low-acid fruit juices could be eliminated by exposure to $600 \mathrm{MPa}$ for $10 \mathrm{~min}$ at $47^{\circ} \mathrm{C}$, while for coffee and Oolong tea, heating to $67^{\circ} \mathrm{C}$ under similar pressure and time conditions was found to be necessary (Farr, 1990). High pressure-processed foods have been available in Japanese markets since 1990 and in the USA and Europe since 1996.

\section{Pulsed electric fields}

The inactivating effect of PEF has been demonstrated on various micro-organisms (Sale \& Hamilton, 1967; Hülsheger et al. 1983). PEF has been investigated as a potential non-thermal technique for food preservation (Ho \& Mittal, 2000). Various studies have demonstrated moderate to significant microbicidal effects by discharging short high-voltage electric pulses through aqueous solutions, e.g. milk, orange juice and various buffer solutions. Earlier research into the use of electricity and PEF for microbial inactivation has been reviewed by Ho \& Mittal (2000). Microbial analysis has been carried out on apple juice, milk ( $2 \%$ fat), whole egg and pea soup subjected to previous processing using electric pulses (Barbosa-Canovas et al. 1999). Various extents of improved shelf-life have been recorded for the PEF-treated samples compared with the untreated ones. PEF has been shown to be ineffective against spore inactivation (Heinz et al. 2001). However, attempts are being made to combine the process with other anti-microbial methods to achieve the desired reduction in spore counts.

\section{Ultrasound}

The lethal effect of ultrasound on some micro-organisms has long been demonstrated. Although ultrasonication has been proposed as a means of sterilisation of liquid foods (Jacobs \& Thornley, 1954), the inactivation of extremely-heat-resistant microbial forms such as bacterial spores would require such drastic ultrasonication treatments that destruction of the physico-chemical characteristics of the food would result. Pressure during heat and ultrasonication (manothermosonication) treatment has been shown to increase the lethality of heat treatment by approximately 10-fold against Bacillus subtilis. The effect of manothermosonication treatments was investigated on some spore-forming bacteria (Bacillus cereus, Bacillus coagulans and Bacillus sterothermophilus), non-spore-forming bacteria (Aeromonas hydrophila) and yeasts (Saccharomyces cerevisiae). In all cases, the lethality of manothermosonication treatments was greater than that of the corresponding heat treatment at the same temperature. The magnitude of this effect depended on the microorganism. Yeasts were the most sensitive to manothermosonication treatments, while spores were the most resistant (Sala et al. 1995). Sala et al. (1995) and I Álvarez (unpublished results) suggested that manosonication and manothermosonication could serve as alternatives to conventional pasteurisation of heat-sensitive foods. The effect of the combined treatment of ultrasound and heat in a continuous process on microbial destruction was demonstrated by the comparison of the integrated timetemperature intensity ( $\mathrm{F}$ value) of each treatment (Fig. 1; Zenker et al. 2001). These results indicated that foods could be processed with ultrasound in combination with heat to maximise product safety. From the few examples summarised earlier it may be suggested that these non-thermal technologies in combination with other mild preservative 
(a)

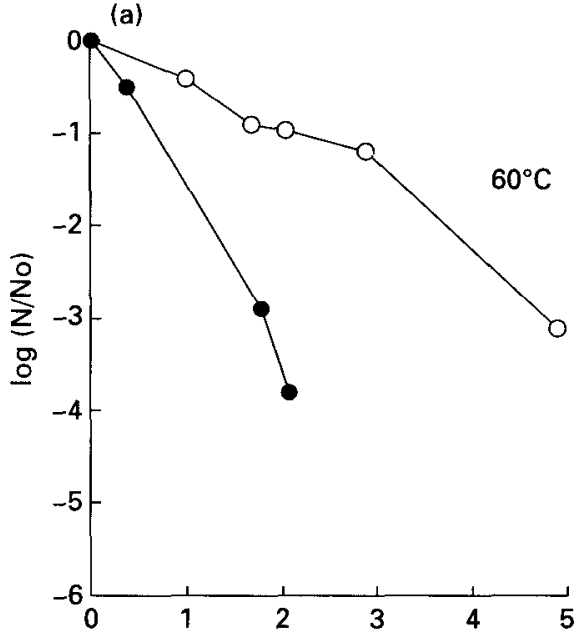

(b)

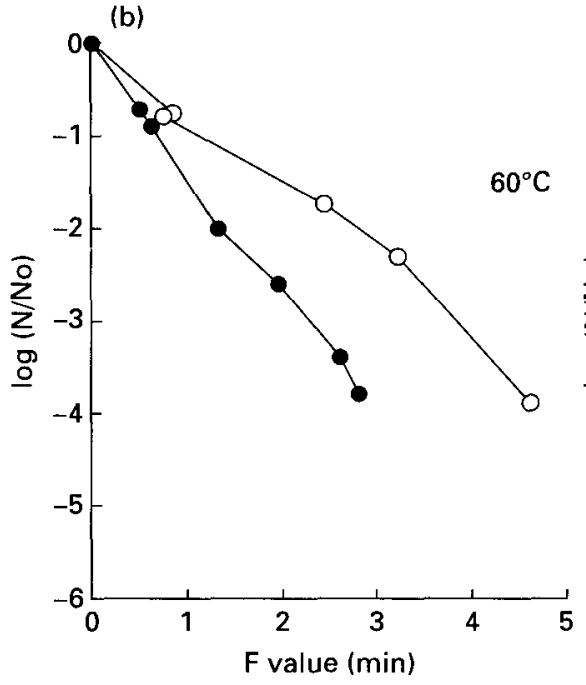

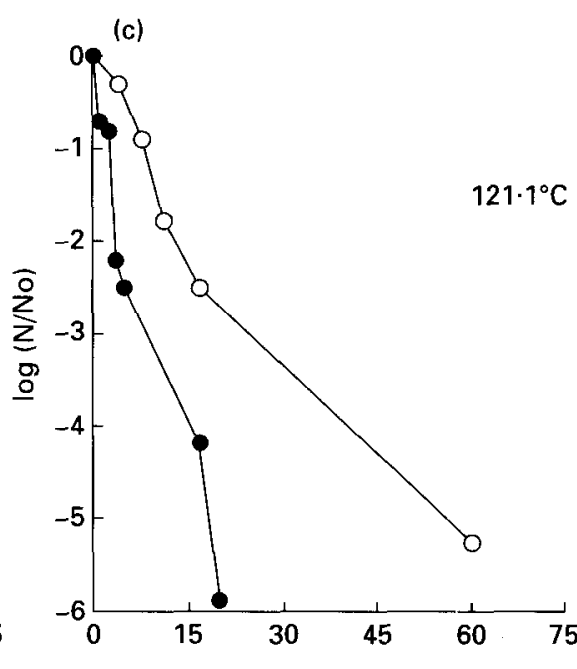

Fig. 1. Effect of combined ultrasonic and conventional heat treatment (๑) in continuous flow on the survival of (a) Escherichia coli $K 12 \mathrm{DH} 5 \alpha$ (b) Lactobacillus acidophilus and (c) Bacillus stearothermophilus in (O), conventional heat treatment. N/No represents the no. of colonies relative to that before treatment and $\mathrm{F}$ value represents the integrated time-temperature intensity in phosphate buffer (pH 7) (from Zenker et al. 2002).

Table 2. Pulsed electric field processing conditions for selected liquid foods (Qin et al. 1995) (Mean values and standard deviations)

\begin{tabular}{|c|c|c|c|c|c|c|c|c|c|c|}
\hline \multirow[b]{2}{*}{ Food } & \multicolumn{2}{|c|}{$\begin{array}{l}\text { Apple juice from } \\
\text { concentrate }\end{array}$} & \multicolumn{2}{|c|}{$\begin{array}{c}\text { Fresh } \\
\text { apple juice }\end{array}$} & \multicolumn{2}{|c|}{$\begin{array}{c}\text { Raw } \\
\text { skimmed milk }\end{array}$} & \multicolumn{2}{|c|}{ Beaten eggs } & \multicolumn{2}{|c|}{$\begin{array}{c}\text { Green peas } \\
\text { (Pisum sativum) }\end{array}$} \\
\hline & Mean & SD & Mean & SD & Mean & $S D$ & Mean & SD & Mean & SD \\
\hline Peak electric field $(\mathrm{kV} / \mathrm{cm})$ & 50 & & 50 & & 40 & & 35 & & 35 & \\
\hline Pulse duration $(\mu \mathrm{s})$ & 2 & & 2 & & 2 & & 2 & & 2 & \\
\hline Pulse no. & 10 & & 16 & & 20 & & 10 & & 32 & \\
\hline Initial temperature $\left({ }^{\circ} \mathrm{C}\right)^{\star}$ & 8.5 & 1.5 & 8.5 & 1.5 & $10 \cdot 0$ & 1.5 & 8.5 & 1.5 & $22 \cdot 0$ & $2 \cdot 0$ \\
\hline Maximum treatment temperature $\left({ }^{\circ} \mathrm{C}\right)^{*}$ & 45 & 5 & 45 & 5 & 50 & 4 & 45 & 5 & 53 & 2 \\
\hline Storage temperature $\left({ }^{\circ} \mathrm{C}\right)$ & $22-25$ & & $4-6$ & & $4-6$ & & $4-6$ & & $4-6$ & \\
\hline Shelf-life (d) & 28 & & 21 & & 14 & & 28 & & 10 & \\
\hline
\end{tabular}

*The range of temperatures were targeted from preliminary experiments so as to minimise thermal degradation.

methods offer the potential of producing processed foods with maximum safety, but without the key disadvantages of conventional preservation processes.

\section{Product quality}

Excessive heating typically causes off-flavour production and other adverse quality changes. Unlike during thermal pasteurisation, the product temperature during HPP or PEF is increased only slightly. Sensory qualities of pressuretreated orange juice were found to be closer to those of freshly-squeezed juice than to those of heat-treated samples (Knorr, 2002). The high quality of these pressurepasteurised products was retained unchanged during storage for $1-3$ months at $5^{\circ} \mathrm{C}$. Room temperature storage, however, resulted in rapid deterioration due to dissolved $\mathrm{O}_{2}$ and remaining enzyme activities (Watanabe et al. 1991; Kimura et al. 1994). Prestamo \& Arroyo (2000) have recently conducted a nutritional study in rats based on the effects on body weight, organs and several serum variables of feeding HPP-treated tofu. They detected differences in the nutritional value of conventionally-produced tofu and HPPtreated tofu. Pressure treatment of various milks (bovine, ewe and goat) produced an increase in casein solubility (Lopez-Fandino et al. 1998). Use of pressure at $>200 \mathrm{MPa}$ increased the protein and water contents of the curd, and consequently enhanced curd yield from ewe's and goat's milk, although coagulation time was not affected by HPP (Lopez-Fandino \& Olano, 1998).

Pectic substances (galacturonic acid) have been reported to be absent in sugarbeet juice extracted after PEF treatment. This finding was attributed to the reduced temperature of the process, which hindered the extraction of pectins into the juice. The absence of pectins in the sugarbeet juices is advantageous for subsequent filtration and purification in the sugar refinery (Bouzrara \& Vorobiev, 2000). Juices are one of the most important areas in beverage production, but one of the drawbacks has been the loss of fresh-like flavour. However, the non-thermal characteristics of PEF permit treatments at low temperatures, thus avoiding the harmful effects of hot filling. Some of the earliest studies on the effects of PEF pasteurisation on the quality and shelf-life of five different products (Table 2) have been reported (Qin et al. 1995). Ma et al. (1997) compared the effect of PEF, HPP and thermal processing on sensory, physical, chemical and microbiological attributes of liquid whole eggs after 
(a)

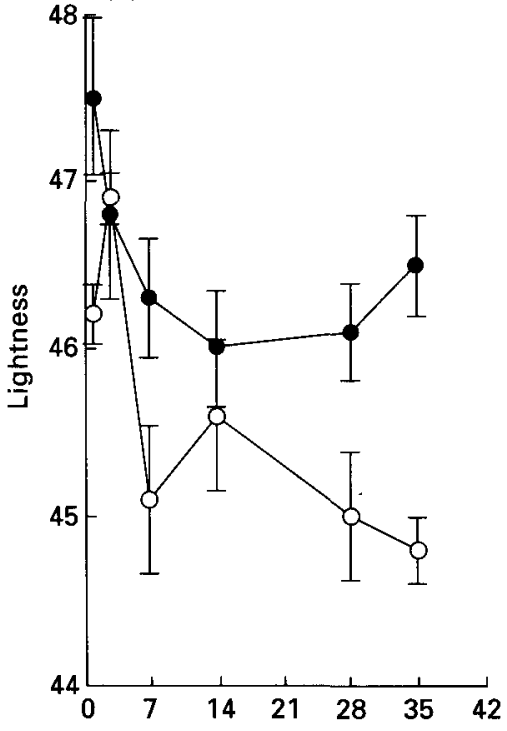

(b)

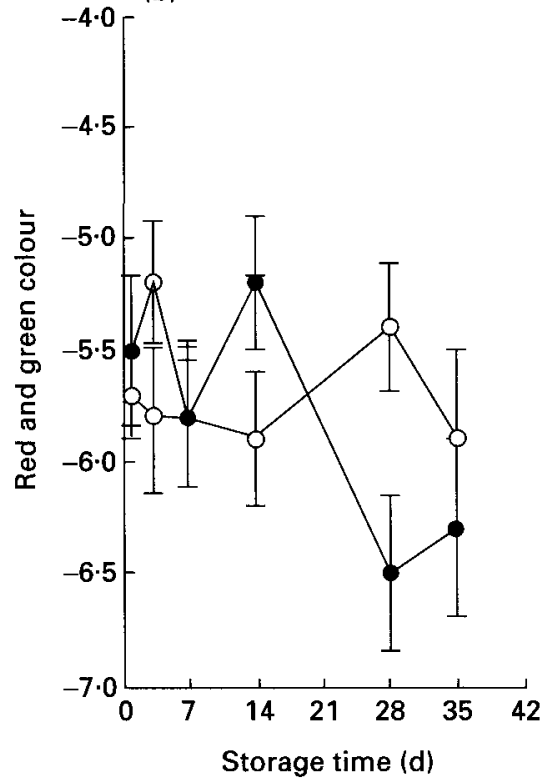

(c)

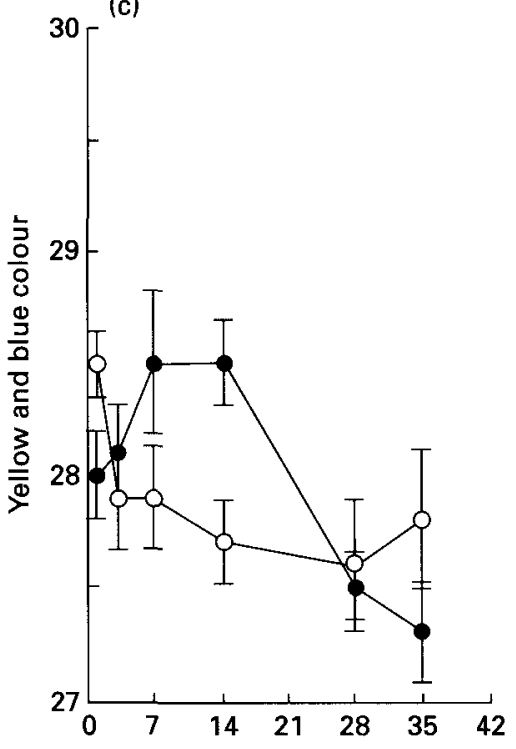

Fig. 2. Results for colour measurement during storage of combined ultrasonic and heat-treated orange juice (e) and conventionallyheated orange juice (O). (a), Lightness; (b), red and green; (c), yellow and blue. The colour dimensions were determined using Chroma-meter CR 200 (Minolta) and the instrumental colour system $L^{*}, a^{\star}, b^{\star}$. Values are means with their standard errors represented by vertical bars. (From Zenker et al. 2001.)

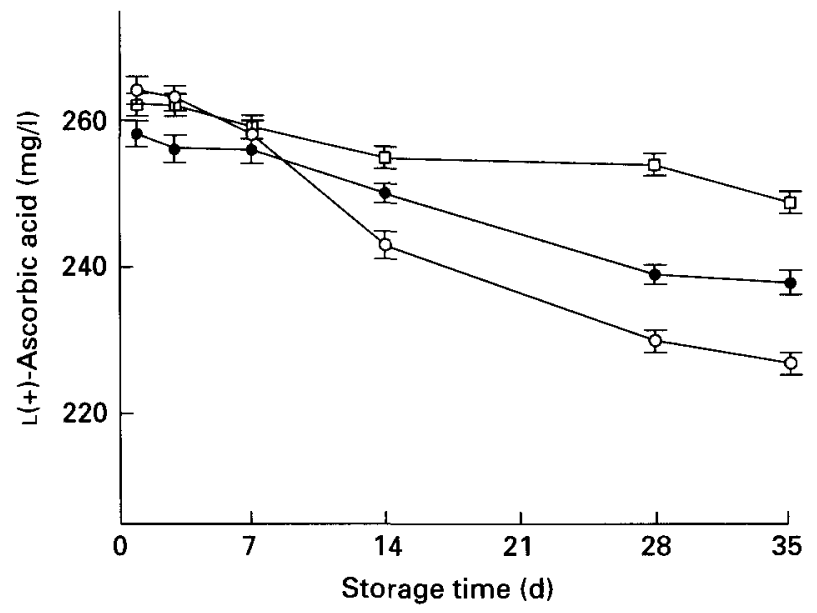

Fig. 3. Degradation of native $L(+)$-ascorbic acid in orange juice after applying a combination of ultrasound and conventional heating in the pilot plant unit. (O), Conventional heating; $(O)$ ultrasound heatassisted treatment; $(\square)$, untreated sample. Values are means with their standard errors represented by vertical bars. (From Zenker et al. 2001.)

PEF in a coaxial continous chamber with twenty pulses of $48 \mathrm{kV} / \mathrm{cm}$ for $2 \mu \mathrm{s}$ in five steps. It was concluded that PEF was suitable for industrial implementation due to the better quality of the liquid whole egg derived by this method compared with the other methods studied. Fig. 2 shows the better retention of colour in the combined heat and ultrasound-treated juice samples with storage when compared with the heat-treated juice samples. Additionally, less reduction was detected in native $L(+)$-ascorbic acid in the combined heat and ultrasound-treated juice samples (Fig. 3; Zenker et al. 2001).

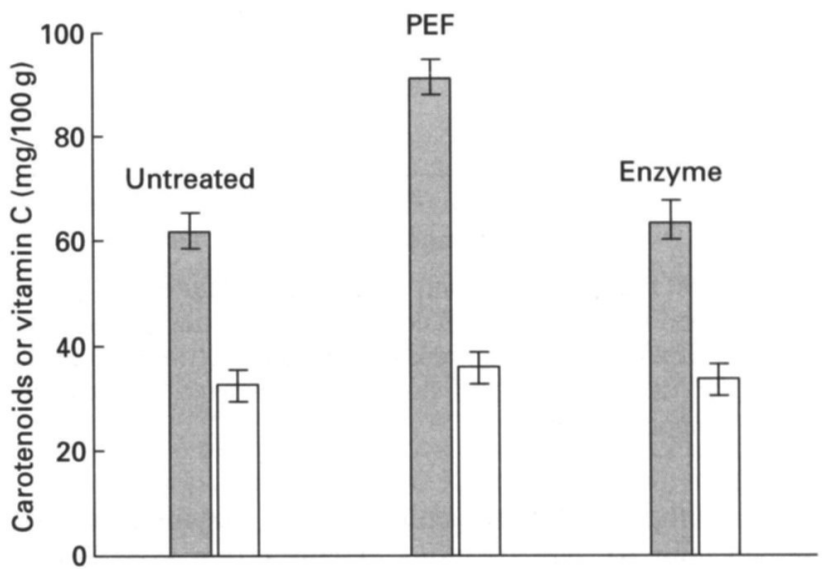

Fig. 4. Influence of pulsed electric field (PEF) or enzyme pretreatment on $\beta$-carotene $(\mathrm{m})$ and vitamin $C(\square)$ in paprika juice. Values are means with their standard errors represented by vertical bars. (From Ade-Omowaye et al. 2001.)

The uniform temperature distribution within foods treated by these non-thermal methods reduces process intensity and consequently enhances quality. There have been many reports of better quality retention of non-thermal processed foods. Kimura et al. (1994) reported that the quality of pressure-processed strawberry jam immediately after manufacture was superior to that of heat-processed jam, preserving the fresh flavour and natural colour of the raw fruits. Pressure-processed guava (Psidium guajava) puree retained the original colour, turbidity, viscosity and chemical components (Yen \& Lin, 1996). Ade-Omowaye et al. (2001) reported higher $\beta$-carotene (approximately one-third) retention in juice derived from PEF-treated red 

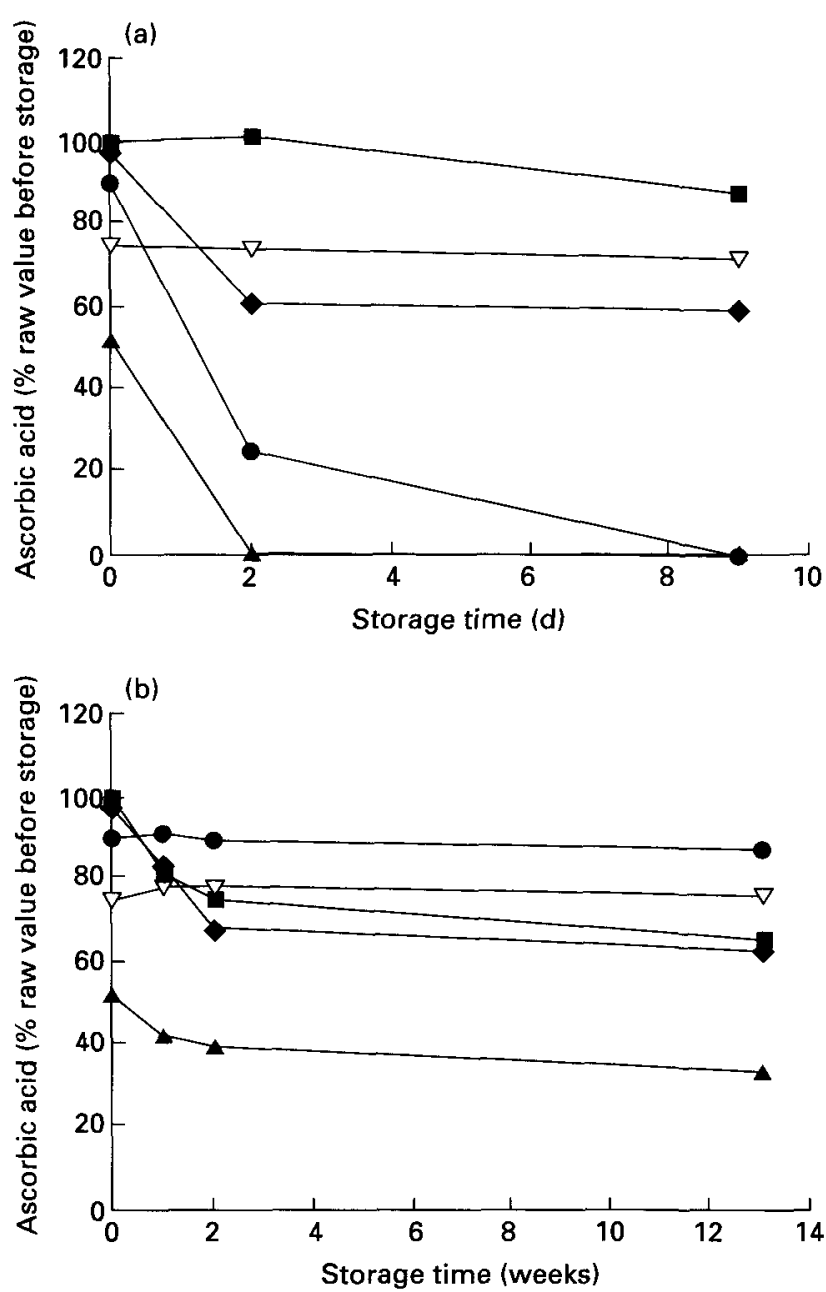

Fig. 5. Effect of storage time and storage temperature $\left(4^{\circ} \mathrm{C}(\mathrm{a})\right.$ and $-30^{\circ} \mathrm{C}(\mathrm{b})$ ) on the ascorbic acid concentration of raw $(\square)$, blanched $100^{\circ} \mathrm{C}$ for $2 \mathrm{~min}(\triangle)$ and high-pressure-treated $(600 \mathrm{mPa}$ for $20 \mathrm{~min}$ at $8(O), 25(\boldsymbol{A})$ and $\left.50^{\circ} \mathrm{C}(\bullet)\right)$ peas (Pisum sativum). (H Koch and D Knorr, unpublished results.)

paprika compared with the untreated and enzyme-pretreated samples (Fig. 4). The vitamin $\mathrm{C}$ retention immediately after PEF pretreatment $(2 \mathrm{kV} / \mathrm{cm}$, energy input per pulse $0.2 \mathrm{~kJ} / \mathrm{kg}$ ) of red bell pepper ranged from $89.6 \%$ to $96.5 \%$, with the sample subjected to fifty pulses having the least retention and that treated with one pulse having the highest retention (BIO Ade-Omowaye et al. (unpublished results)).

Controlled monitoring of the pressure-promoted stress reaction of plants can lead to stimulation of the 'plant bioreactor systems' to increase biosynthesis of desired plant metabolites (Knorr, 1999). Also, PEF treatment induced a time-dependent increase in the extent of membrane permeabilisation. This increased permeabilisation is most probably due to induction of enzyme activities, which also result in degradation of plant cell wall biopolymers such as pectins. Such degradation products produced in response to stressors such as high pressure or PEF seem to induce time-delayed biosynthetic activities in the plant cells, resulting, for example, in the production of anti-microbials (Shreck et al.

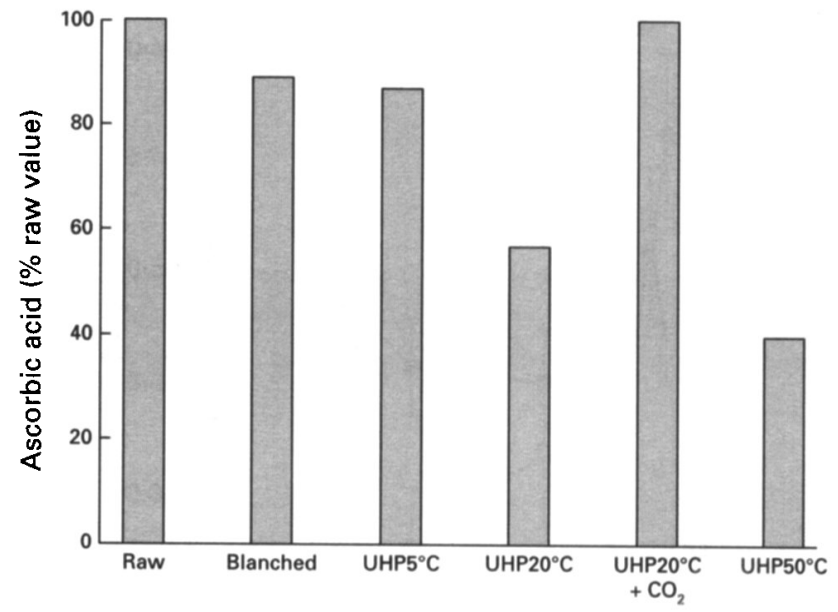

Fig. 6. Ascorbic acid concentrations of raw, blanched $100^{\circ} \mathrm{C}$ for $2 \mathrm{~min}$ and high-pressure-treated broccoli $(600 \mathrm{mPa}$ for $20 \mathrm{~min}$ (UHP) at 5,20 and $50^{\circ} \mathrm{C}$ ) packaged in air or in carbon dioxide $\left(20^{\circ} \mathrm{C}\right)$. (From $H$ Koch and D Knorr, unpublished results.)

1996). Vitamin C concentrations in HPP-treated peas (Pisum sativum), as influenced by storage time and storage temperature, are shown in Fig. 5 (H Koch and D Knorr, unpublished results). Pressure treatment of broccoli in an atmosphere of $\mathrm{CO}_{2}$ resulted in complete retention of ascorbic acid (Fig. 6; H Koch and D Knorr, unpublished results).

\section{Process development}

Pressure-induced phase transitions such as crystallisation of lipids or thawing or freezing of high-moisture systems offer numerous opportunities for process or product development. Employing non-thermal methods to synthesise bioactive compounds in foods that are of great nutritional benefit to the consumer can provide attractive opportunities for the food industry. The use of dense gases, such as supercritical $\mathrm{CO}_{2}$, and high-pressure homogenisation as additional methods of food preservation could also be exploited.

\section{Future research needs}

More targeted and systematic research efforts towards commercial products, in terms of their safety, functionality and nutritional quality, are needed to convince regulatory authorities and consumers that these non-thermal-processed products, in addition to their novelty, are safe, nutritious and of better quality. Further studies on kinetic data associated with the impact of high pressure on bioactive components in various food systems are needed. Nutritional aspects of these non-thermally-treated foods have been neglected in non-thermal research, suggesting more work is still required in this area. More information on interactions between these processes and toxins or allergens is also needed. Interactions between electrode materials and foods during PEF treatment should be examined, and systematic work on safety issues (e.g. on free-radical production) should be carried out to assure regulatory approval. 


\section{Conclusion}

The key advanced technologies discussed offer the potential for processing a wide range of foods, and provide the opportunity to produce processed foods with high safety together with improved sensory and nutritional qualities as compared with their conventionally-processed counterparts. However, combination of these processes with mild preservative methods are necessary to obtain complete sterilisation. Also, low-temperature storage and distribution are needed to retain their sensory characteristics.

\section{References}

Ade-Omowaye BIO, Angersbach A, Taiwo KA \& Knorr D (2001) The use of high intensity electric field pulses in producing juice from paprika. Journal of Food Processing and Preservation 25, 353-365.

Barbosa-Canovas GV, Gongora-Nieto MM, Pothakamury UR \& Swanson EG (1999) Preservation of Foods with Pulsed Electric Field. San Diego, CA: Academic Press.

Barsotti L \& Cheftel JC (1999) Food processing by pulsed electric fields: Biological aspects. Food Review International 15, 181-213.

Bouzrara H \& Vorobiev E (2000) Beet juice extraction by pressing and pulsed electric fields. International Sugar Journal 102, 195-200.

Chang DC, Chassy BM \& Saunders JA (1992) Guide to Electroporation and Electrofusion. San Diego, CA: Academic Press Inc.

Farr D (1990) High pressure technology in the food industry. Trends in Food Science and Technology 1, 14-16.

Hayashi R (1996) An overview of the use of high pressure in bioscience and biotechnology. In High Pressure Bioscience and Biotechnology, pp. 1-6 [R Hayashi and C Balny, editors]. Amsterdam: Elsevier Science Publishers.

Heinz V, Alvarez I, Angersbach A \& Knorr D (2001) Preservation of liquid foods by high intensity pulsed electric fields - basic concepts for process design. Trends in Food Science and Technology 12, 103-111.

Hoover DG (1997) Minimally processed fruits and vegetables: reducing microbial load by nonthermal physical treatments. Food Technology 51, 66-71.

Hoover DG, Metrick C, Papineau AM, Farkas DF \& Knorr D (1989) Biological effects of high hydrostatic pressure on food micro-organisms. Food Technology 43, 99-107.

Ho S \& Mittal GS (2000) High voltage pulsed electrical field for liquid food pasteurisation. Food Reviews International 16, 395-434.

Horie Y, Kimura K, Ida M, Yosida Y \& Ohki K (1991) Jam preparation by pressurisation. Nippon Nogeikagaku Kaishi $\mathbf{6 5}$, 975-980.

Hülsheger H, Potel J \& Niemann EG (1983) Electric field effects on bacteria and yeast cells. Radiation and Environmental Biophysics 22, 149-162.

Jacobs SE \& Thornley MJ (1954) The lethal action of ultrasonic waves on bacteria suspended in milk and other liquids. Journal of Applied Bacteriology 17, 38-55.

Kimura K, Ida M, Yoshida Y, Ohki K, Fukumoto T \& Saui N (1994) Comparison of keeping quality between pressure processed and heat processed jam: changes in flavour components, hue and nutritional elements during storage. Bioscience Biotechnology Biochemistry 58, 1386-1391.

Knorr D (1995) Hydrostatic pressure treatment of food: microbiology. In New Methods of Food Preservation, pp. 159-175 [GW
Gould, editor]. London: Blackie Academic and Professional Publisher.

Knorr D (1996) Advantages, opportunities and challenges of high hydrostatic pressure application to food systems. In High Pressure Bioscience and Biotechnology, pp. 279--287 [R Hayshi and C Balny, editors]. Amsterdam: Elsevier Science Publishers.

Knorr D (1999) Novel approaches in food processing technology: new technologies for preserving foods and modifying function. Current Opinion in Biotechnology 10, 485-491.

Knorr D (2002) Effects of non-thermal treatments and storage on bioactive compounds. In Effects of Food Processing on Bioactive Compounds in Foods [TC Lee, editor]. Washington, DC: American Chemical Society. (In the Press).

Knorr D \& Angersbach A (1998) Impact of high electric field pulses on plant membrane permeabilisation. Trends in Food Science and Technology 9, 185-191.

Lopez-Fandino R \& Olano A (1998) Cheese making properties of ovine and caprine milks subjected to high pressure. Lait $\mathbf{7 8}$, 341-350.

Lopez-Fandino R, Ramos M \& Olano A (1998) Distribution of minerals and proteins between the soluble and colloidal phases of pressurised milks from different species. Journal of Dairy Research 65, 69-78.

Ma L, Chang FJ \& Barbosa-Canovas GV (1997) Inactivation of $E$. coli in liquid whole eggs using pulsed electric fields technology. New frontiers in food engineering. In Proceedings of the Fifth Conference of Food Engineering, pp. 216-221 [GV Barbosa-Canovas, $S$ Lombardo, $G$ Narsimhan and $M$ Okos, editors]. New York: American Institute of Chemical Engineers.

McClements DJ (1995) Advances in the application of ultrasound in food analysis and processing. Trends in Food Science and Technology 6, 293-299.

Mertens B (1995) Hydrostatic pressure treatment of food: equipment and processing. In New Methods of Food Preservation pp. 135-158 [GW Gould, editor]. London: Blackie Academic and Professional Publisher.

Meyer RS, Cooper KL, Knorr D \& Lelieveld H (2000) High pressure sterilisation of foods. Food Technology 54, 67-72.

Neumann E, Sowers AF \& Jordan CA (1989) Electroporation and Electrofusion in Cell Biology. New York: Plenum Press.

Ogawa H, Fukuhisha K \& Fukumoto H (1992) Effect of hydrostatic pressure and preservation of citrus juice. In High Pressure and Biotechnology, pp. 269-277 [C Balny, R Hayashi, K Hereman and D Massons, editors]. Montrouge, France: John Libbey Eurotext.

Ohlsson T (1994) Minimal processing - preservation methods of the future: an overview. Trends in Food Science and Technology 5, 341-344.

Prestamo G \& Arroyo G (2000) Biological response of rats fed with tofu treated with high hydrostatic pressure. Journal of Agricultural and Food Chemistry 48, 4641-4646.

Qin BL, Pothakamury UR, Vega-Mercado H, Martin-Belloso OM, Barbosa-Canovas GV \& Swanson BG (1995) Food pasteurisation using high intensity pulsed electric fields. Food Technology 12, 55-60.

Sala FJ, Burgos J, Condon S, Lopez P \& Raso J (1995) Effect of heat and ultrasound on microorganisms and enzymes. In New Methods of Food Preservation, pp. 177-203 [GW Gould, editor]. London: Blackie Academic and Professional Publisher.

Sale AJH \& Hamilton WA (1967) Effects of high electric fields on micro-organisms: Killing of bacteria and yeasts. Biochimica et Biophysica Acta 148, 781-788.

Schreck S, Dörnenburg H \& Knorr D (1996) Evaluation of hydrogen production in tomato (Lycopersicon esculentum) suspension cultures as a stress reaction to high pressure treatment. Food Biotechnology 10, 163-171. 
Stute R, Eshtiaghi MN, Boguslawski S \& Knorr D (1996) High pressure treatment of vegetables. In High Pressure Chemical Engineering, pp. 271-276 [Ph Rudolf von Rohr and Ch Trepp, editors]. Amsterdam: Elsevier Science.

Styles MF, Hoover DG \& Farkas DF (1991) Response of Listeria monocytogenes and Vibrio para haemolyticus to high hydrostatic pressure. Journal of Food Science 56, 1404-1407.

Thakur BR \& Nelson PE (1998) High pressure processing and preservation of food. Food Review International 14, 427-447.

Watanabe M, Arai E, Kumeno K \& Homma K (1991) A new method for producing non heated jam sample: The use of freeze concentration and high pressure sterilisation. Biological Chemistry 55, 2175-2176.

Yen GC \& Lin HT (1996) Comparison of high pressure treatment and thermal pasteurisation effects on the quality and shelf life of guava puree. International Joumal of Food Science and Technology 31, 205-213.

Zenker M, Heinz V \& Knorr D (2001) Combined application of ultrasound and temperature for energy-saving and mild preservation of liquid food. Conference Proceedings of the 3rd European Congress of Chemical Engineering, Nuremberg, Germany. 